\title{
Review
}

\section{The diverse and contrasting effects of using human prostate cancer cell lines to study androgen receptor roles in prostate cancer}

\author{
Sheng-Qiang $\mathrm{Yu}^{1,2, *}$, Kuo-Pao Lai ${ }^{2, *}$, Shu-Jie Xia ${ }^{1}$, Hong-Chiang Chang ${ }^{3}$, Chawnshang Chang ${ }^{2}$, Shuyuan Yeh $^{2}$ \\ ${ }^{1}$ Department of Urology, The First People's Hospital of Shanghai Jiao Tong University, Shanghai 200080, China \\ ${ }^{2}$ George Whipple Laboratory for Cancer Research, Departments of Pathology and Urology, The Cancer Center, University \\ of Rochester, Rochester, NY 14642, USA \\ ${ }^{3}$ Department of Urology, National Taiwan University/Hospital, Taipei 100, Taiwan, China
}

\begin{abstract}
The androgen receptor (AR) plays an important role in the development and progression of prostate cancer (PCa). Androgen deprivation therapy is initially effective in blocking tumor growth, but it eventually leads to the hormonerefractory state. The detailed mechanisms of the conversion from androgen dependence to androgen independence remain unclear. Several PCa cell lines were established to study the role of AR in PCa, but the results were often inconsistent or contrasting in different cell lines, or in the same cell line grown under different conditions. The cellular and molecular alteration of epithelial cells and their microenvironments are complicated, and it is difficult to use a single cell line to address this important issue and also to study the pathophysiological effects of AR. In this paper, we summarize the different effects of AR on multiple cell lines and show the disadvantages of using a single human PCa cell line to study AR effects on PCa. We also discuss the advantages of widely used epithelium-stroma co-culture systems, xenograft mouse models, and genetically engineered PCa mouse models. The combination of in vitro cell line studies and in vivo mouse models might lead to more credible results and better strategies for the study of AR roles in PCa.
\end{abstract}

Asian Journal of Andrology (2009) 11: 39-48. doi: 10.1038/aja.2008.44; published online 22 December 2008.

Keywords: androgen receptor, cell lines, epithelium-stroma co-culture, mouse models, prostate cancer

\section{Introduction}

Prostate cancer $(\mathrm{PCa})$ is one of the most common cancers in the Western world and has an increasing incidence in the Asian countries [1]. The androgen receptor (AR) is important in the development and progression

Correspondence to: Prof. Chawnshang Chang and Prof. Shuyuan Yeh, George Whipple Laboratory for Cancer Research, Departments of Pathology and Urology, Medical Center, University of Rochester, Box 626, 601 Elmwood Avenue, Rochester, NY 14642, USA.

Fax: +1-585-756-4133

E-mail: chang@urmc.rochester.edu (Chawnshang Chang)or Shuyuan_yeh@urmc.rochester.edu (Shuyuan Yeh)

${ }^{*}$ These two authors contributed equally to this paper.

Received: 8 November 2008 Accepted: 9 November 2008

Published online: 22 December 2008 of PCa [2]. Since the first observation by Huggins and Hodges [3] in 1941, androgen deprivation therapy (ADT) has become the major therapeutic option for advanced PCa. Although initially effective at blocking tumor growth, ADT eventually fails, leading to a state of hormonerefractory PCa (HRPC) [4]. However, the AR continues to be expressed in most cells of the HRPCs [5], and the detailed mechanisms involved in the conversion from androgen dependence $(\mathrm{AD})$ to androgen independence in PCa remain unclear. Several papers $[2,6-8]$ have proposed possible mechanisms for this transition, such as: (1) AR mutation, with AR acquiring promiscuous binding to other steroids; (2) imbalance of AR co-regulators, causing abnormal alteration of AR transactivation; (3) alteration of selective androgen/AR signal transduction pathways through nonandrogen induction; and (4) changes in the surrounding 
microenvironment and stromal cells.

Several PCa cell lines were established to study the role of $\mathrm{AR}$ in $\mathrm{PCa}$ [9], but the results were often inconsistent or even contrasting in different cell lines, or in the same cell line grown under different conditions. The cellular and molecular alterations of epithelial cells and their microenvironments during cancer development are complicated, and it is difficult to use a single cell line to study these changes and also to study the pathophysiological effects mediated by AR. Cell lines derived from different PCa hosts have their own characteristics and may be representative of different stages of PCa [9]. Furthermore, most of these cell lines are grown under in vitro culture conditions; the in vitro cell line data might not reflect the real physiological status accurately. In this paper, we summarize the data obtained from a variety of cell lines with respect to the role of AR in cancer development, show the disadvantages of using a single human PCa cell line to study AR effects on PCa, and examine the widely used epithelium-stroma co-culture systems and genetically engineered PCa mouse models.

\section{The role of AR in different PCa cell lines}

\subsection{LNCaP cells}

LNCaP cells, isolated from a human PCa lymph node metastasis [10], are CK5-negative and CK8/18-positive [9]. These cells express a mutant AR (T877A) [11] and respond to androgens/AR signals differentially depending on the passage number or culture conditions.

Androgen/AR signaling is required for androgensensitive LNCaP cells to proliferate. Yang et al. [12] and Compagno et al. [13] reported that the use of small interfering RNA (siRNA) to suppress endogenous AR in LNCaP cells led to apoptosis without proliferation. Similar results were also reported by Liao et al. [14] and Haag et al. [15]. Eder et al. [16] inhibited AR expression in LNCaP cells using antisense AR oligodeoxynucleotides and reduced AR expression to approximately $2 \%$ of normal levels within $24 \mathrm{~h}$. They found that down-regulating AR significantly inhibited LNCaP cell growth, strongly reduced secretion of the androgen-regulated prostatespecific antigen and increased the level of cell apoptosis [16]. Eder et al. [17] further investigated the effects of AR knockdown on prostate tumor growth in vivo using a mouse xenograft model. They found that treatment with AR antisense oligodeoxynucleotides could knock down AR expression and result in significant inhibition of tumor growth. Together, the above data suggest that the AR can function as a key survival factor for androgen-sensitive LNCaP cells, both in vitro and in vivo. These conclusions were consistent with the clinical finding that ADT therapy could dramatically reduce the volume of androgendependent prostate tumors.
Androgen-dependent LNCaP cells cultured in androgen-free medium for several months $[18,19]$ or isolated from castrated mouse xenograft tumors [20] developed several androgen-independent sublines. Yuan et al. [21] reported that this long-term androgen deprivation could induce epithelial neuroendocrine (NE) differentiation of androgen-sensitive LNCaP cells. The authors further proposed that the NE differentiation might contribute to the hormone-refractory growth of PCa. In the androgenindependent sublines of LNCaP cells, an androgen/AR signal was reported [22-24] to function not as a stimulator or survival factor, but as a suppressor of cell proliferation. Similar changes in AR function, from proliferation stimulator to suppressor, have also been reported in $\mathrm{LNCaP}$ xenografts in vivo after castration [24, 25]. Joly-Pharaboz et al. [26] reported that androgen could suppress the growth of androgen-independent $\mathrm{LNCaP}$ cells in vitro and in vivo. However, they also found that some androgenindependent tumors contained androgen-responsive cells that could escape the androgen suppression.

The responsiveness of the LNCaP cells to androgen/ AR signals might be different among cells from the same xenograft tissue. For example, the AR-positive LNCaPFGC and LNCaP-LNO cell lines were derived from the same biopsy specimen but exhibited different proliferative responses to androgen [27]. Cell proliferation was inhibited by androgen-free medium in the LNCaP-FGC cells, but not in LNCaP-LNO cells [27]. Physiological androgen concentrations induced a proliferative shutoff $\left(\mathrm{G}_{1}\right.$ arrest $)$ in both LNCaP-LNO cells and LNCaP-FGC cells. This $\mathrm{G}_{1}$ arrest was reversed by androgen withdrawal in LNCaP-LNO cells, but not in LNCaP-FGC cells [27].

Collectively depending on the cell environment or passage number, the AR might function as a cell survival factor, stimulator or suppressor for LNCaP cells. The transformation of LNCaP cells from androgen dependence to independence could closely mimic the transformation of clinical PCa after ADT therapy. The AR in LNCaP cells, however, contained a mutation $(T 877 A)$ in the ligand-binding domain that affected the steroid-binding characteristics. Androgens could activate the mutated AR at lower concentrations. Progestogens, estrogens and several antiandrogens could also bind to the mutated AR and activate the AR transcriptional functions [11]. In the clinical setting, AR mutations were found in only $0 \%-4 \%$ of latent and stage B prostate tumors [28-30] but existed in $21 \%-44 \%$ of metastatic tumors sampled before therapy [29, 31]. Therefore, the LNCaP and derived cells might not be able to mimic the entire spectrum of clinical PCa stages.

\subsection{PC3 cells}

PC3 cells, isolated from a human PCa bone metastasis with high malignancy [32], express both CK5 and CK8/18 [9]. 
PC3 cells are androgen-insensitive and lack expression of the AR protein [9].

PC3 cells were widely used to study HRPC or to study the role of AR in HRPC by transfection of functional human AR complementary DNA (cDNA) [33-37]. Expression of AR in PC3 cells either suppresses or slightly promotes cell proliferation [33-36], depending on which promoter drives the expression of the AR protein. Similar results were reported, with androgen suppressing the proliferation of PC3-AR cells using the simian virus 40 (SV40) promoter [34], the cytomegalovirus (CMV) promoter [36] or the EF1a promoter [33]. In these studies, expression of AR was artificially controlled by a strong and unnatural promoter. Therefore, the results might not represent the control of AR function under physiological and cellular conditions. Altuwaijri et al. [35] established the PC3AR9 cell line, in which expression of human AR was driven by the natural human AR promoter. They found that treatment with dihydroxytestosterone (DHT) resulted in mild promotion, but not suppression, of growth in PC3AR9 cells. The contrasting results suggested that the promoter was important and might influence AR function in $\mathrm{PCa}$ cells.

On evaluating the effects of AR in the PC3-AR9 cells, we found lower mobility in 'wound'-healing assays and fewer colonies in anchor-independent soft agar assays compared with PC3 cells transfected with control vector only (PC3-v cells) (Chang et al., unpublished data). In the chamber invasion assay, PC3-AR9 cells were significantly less invasive than PC3-v cells. In the bone-wafer resorption assay, PC3-AR9 cells showed decreased osteoclast lacunae on the bone wafer compared with PC3-v cells [38]. After injection into the tibia of athymic nude mice, PC3-AR9 tumors were less aggressive and less invasive than PC3-v tumors [38]. Using a prostate orthotopic xenograft model, PC3-v and PC3-AR9 cells were inoculated directly into the anterior prostate of nude mice. After 12 weeks, we found significantly larger primary prostate tumors and metastatic lymph nodes with PC3-v cells than with PC3-AR9 cells [38]. The findings from restoring the AR in PC3 cells suggested that the androgens/AR signaling could suppress the PC-3AR9 cells' invasion ability, both in vitro and in vivo.

The expression of $\mathrm{AR}$, driven by its natural promoter, resulted in increased growth of PC3-AR9 cells in vitro in the presence of $1 \mathrm{nmol} \mathrm{L}^{-1}$ DHT [35]. However, using the orthotopic xenograft model, we found that PC3-AR9 cells formed smaller primary tumors than PC3-v cells. One explanation for these contrasting in vivo and in vitro findings might be that the in vivo study is a relatively long-term condition, and primary tumor growth could be influenced by the prostate microenvironments. In contrast, in vitro growth is measured under simplified, non-physiological conditions. Our results suggest that the long-term comparison of in vivo tumor cell growth might lead to more accurate assessment than the short term in vitro growth assay.

From the above data, we found that the roles of AR in PC3 cells contrasted with the classical concept that the AR functions as a stimulator in prostate tumor growth and metastasis. These were consistent, however, with the clinical findings that ADT therapy was only effective at blocking tumor growth initially, but failed or even promoted tumor progression at the later stages [39]. Some studies reported that the prostatic epithelial-basal cell marker increased in ADT-refractory tumors [40, 41]. Owing to the expression of both the luminal markerCK8/18 and the basal marker-CK5 [9], PC3 cells might have some basal cell properties. Recently, we also used the prostate epithelial-specific AR-knockout transgenic mouse model of prostate (TRAMP) model and found that the epithelial AR might act as a suppressor in the proliferation or invasion of basal cells [38].

\subsection{DU145 cells}

DU145 cells, derived from a brain metastasis of human $\mathrm{PCa}$ [42], express both CK5 and CK8/18 [6]. DU145 cells are androgen-insensitive and lack the expression of AR protein (methylation of the AR promoter prevents the AR expression) [43].

As DU145 cells do not express AR and exhibit no response to androgen treatment, Scaccianoce et al. [44] established the DU145-AR cell line by stable transfection of a functional human AR cDNA. They found that the untreated DU145-AR cells showed a lower proliferation rate than mock-transfected cells. However, when these cells were treated with testosterone, the proliferation rate and other properties were restored [44]. These results indicate that the inactivated AR functioned as a suppressor in the proliferation of DU145-AR cells. In contrast, Litvinov et al. [33] reported that expression of AR in DU145 cells had no effect on cell growth in the presence or absence of androgens. Thus, the AR role in DU145 cells is still obscure. Although the PC3 and DU145 cells were both androgen-independent and basal intermediate-like tumor cells, the AR had different effects in the two cell lines. This illustrates the disadvantage of using a single cell line to study the role of AR in PCa.

In addition to proliferation, the AR also had an effect on the invasion or migration abilities of DU145 cells. Nagakawa et al. [45] reported that the AR might negatively regulate invasion in DU145-AR cells by influencing the expression of specific integrin subunits. Treatment with DHT further inhibited the invasive ability of DU145AR cells. Akashi et al. [46] reported that expression of AR down-regulated the migratory responses of DU145 cells through chemokines and their receptor systems. The 
above reports indicate that AR might suppress the invasion or migration abilities of DU145 cells.

\subsection{CWR22Rv1 cells}

The CWR22Rv1 cells were derived from a recurrent tumor, following ADT of a CWR22 xenograft, which was originally established from a human prostate primary tumor [47-49]. CWR22Rv1 cells are CK5-negative and CK8/18positive, and express a mutant $114-\mathrm{kDa}$ AR (an in-frame duplication of exon 3 of AR gene, which results in the insertion of 39 amino acids in the DNA-binding domain) [9, 43, 47].

Although they express a functional AR, CWR22Rv1 cells are androgen-independent [47]. The CWR22Rv1-AR repertoire displayed dose-dependent, androgen-responsive transcriptional transactivation in reporter assays [50]. The CWR22Rv1 cells could grow well in androgen-free medium, but the growth was weakly stimulated by DHT $[47,50]$.

Using a homologous gene recombination strategy [51], we knocked down the AR in CWR22Rv1 cells and established CWR22Rv1-AR ${ }^{+-}$cell line with much lower AR levels. CWR22Rv1-AR ${ }^{+/}$cells grew much more slowly than the parental CWR22Rv1-AR cells in $10 \%$ fetal bovine serum RPMI medium in vitro (Chang et al., in preparation). However, in a prostate orthotopic xenograft model, we found that CWR22Rv1-AR ${ }^{+/-}$cells produced bigger primary tumors than parental CWR22Rv1 cells (Chang et al., in preparation).

In the Boyden chamber invasion assay, CWR22Rv1$\mathrm{AR}^{+-}$cells were more invasive than parental CWR22Rv1 cells [38]. To further confirm the role of AR in CWR22Rv1 invasion, we restored the AR in CWR22Rv1-AR ${ }^{+-}$cells through a retroviral vector, and the resultant cells were less invasive than the parental cells transfected with the control vector [38]. In contrast, when we knocked down the AR in CWR22Rv1 cells with siRNA, the resultant cells were more invasive than the parental cells transfected with scrambled RNA [38]. In the orthotopic inoculation mouse model, CWR22Rv1-AR ${ }^{+/}$cells also produced more and bigger metastatic tumors than CWR22Rv1 cells (Chang et al., in preparation).

Altogether, the above data indicate that the AR functioned as a suppressor of cancer progression and metastasis in the androgen-independent CWR22Rv1 cells. However, a contrast was seen in the growth patterns of CWR22Rv1 and CWR22Rv1-AR ${ }^{+-}$cells by in vitro and in vivo studies. This was similar to the PC3-AR9 cell growth pattern in vitro and in vivo. The contrasting results again suggest that there were some disadvantages in merely depending on in vitro assays to assess the cell growth patterns. The long-term in vivo tumor cell growth might lead to more accurate assessment than the short-term in vitro assay.

\subsection{PC346C cells}

PC346C cells isolated from a human prostate primary tumor through xenograft $[52,53]$ are CK5-negative and CK8/18-positive [9]. The PC346C cells are androgendependent, with the expression of wild-type (wt) AR [9, 54].

Optimal proliferation of PC $346 \mathrm{C}$ requires androgens and is inhibited by antiandrogens [54] similar to the clinical androgen-dependent PCa. Three androgen-independent sublines were derived from PC346C on long-term in vitro androgen deprivation: PC346DCC, PC346Flu1 and PC346Flu2. The PC346DCC subline was derived from a single androgen-deprived condition, and the PC346Flu1 and PC346Flu2 sublines were derived from androgendepleted medium supplemented with hydroxyflutamide [54]. Each subline had different AR levels and different responses to androgen. In PC346DCC, the AR protein was downregulated to very low levels; in contrast, the AR protein in PC346Flu1 was upregulated by about fourfold, but in PC346Flu2 it remained similar to the parental PC346C [54]. PC346DCC exhibited totally androgeninsensitive characteristics, with rapid proliferation in androgen-free medium, unresponsiveness to either androgens or hydroxyflutamide, and robust growth in castrated mice. PC346-Flu1 grew well in androgen-free medium, but was inhibited by physiological androgen concentrations; PC346Flu2 showed growth stimulation with both androgen and hydroxyflutamide [54]. Interestingly, androgen/AR signals played three different roles, no response, stimulator or suppressor, in three different sublines derived from the same parental cell lines. These different phenotypes might be the result of PCa cells adapting to their different extracellular microenvironments.

\subsection{Summary}

From the above discussion, we show that different cell lines have different characteristics and different androgen/ AR responsiveness (Table 1). LNCaP and PC346C are androgen-dependent cells, whereas PC3, DU145 and CWR22Rv1 are androgen-independent cells. LNCaP, CWR22Rv1 and PC346C cells are luminal-like cells, whereas PC3 and DU145 cells are basal intermediatelike cells. LNCaP and CWR22Rv1 express mutant AR; PC346C expresses wt AR; and PC3 and DU145 do not express endogenous AR protein [9]. The AR plays different roles (no response, stimulator or suppressor) in different cell lines and sublines, and also in different culture conditions. No individual cell line could adequately represent the behavior of clinical PCa. Using a single cell line to study the role of AR in human PCa has obvious biases and disadvantages. Therefore, it is important to conduct in vitro epithelium-stroma co-culture systems and in vivo animal models of $\mathrm{PCa}$ to fully probe the 
Table 1. Characteristics of five human prostate cancer (PCa) cell lines.

\begin{tabular}{|c|c|c|c|c|}
\hline Cell lines & Origin [9] & Differentiation marker [9] & AR status [9] & AR roles \\
\hline LNCaP & Lymph node metastasis & CK5 (-) CK8 (+) & Mutant AR & $\begin{array}{l}\text { In androgen-sensitive LNCaP cells: survival } \\
\text { factor and stimulator [12-17]; } \\
\text { In androgen-insensitive LNCaP cells: } \\
\text { suppressor [22-26]; }\end{array}$ \\
\hline PC3 & Bone metastasis & CK5 $(+) \operatorname{CK} 8(+)$ & Negative & $\begin{array}{l}\text { In PC3-AR9 cells with natural AR promoter: } \\
\text { mild stimulator of in vitro growth [35], suppressor } \\
\text { of in vivo growth [38], suppressor of in vitro } \\
\text { and in vivo metastasis [38]; } \\
\text { In PC3-AR cells with unnatural AR promoter, } \\
\text { suppressor of in vivo and in vitro growth [33-37]; }\end{array}$ \\
\hline DU145 & Brain metastasis & CK5 (+) CK8 (+) & Negative & $\begin{array}{l}\text { Scaccianoce et al. [44] reported inactivated AR } \\
\text { functioning as suppressor in DU145-AR-cell } \\
\text { proliferation, but restored by treatment with } \\
\text { testosterone; } \\
\text { Litvinov et al. [33] reported that AR in DU145- } \\
\text { AR cells had no effect on cell growth in the } \\
\text { presence or absence of androgens; } \\
\text { Suppressor of in vitro metastasis }[45,46] \text {; }\end{array}$ \\
\hline CWR22Rv1 & $\begin{array}{l}\text { Xenograft from human } \\
\text { prostate primary tumor }\end{array}$ & CK5 (-) CK8 (+) & Mutant AR & $\begin{array}{l}\text { Stimulator of in vitro growth }[47,50] \text {; } \\
\text { Suppressor of in vivo growth (Chang et al., in } \\
\text { preparation); } \\
\text { Suppressor of in vitro [38] metastasis; } \\
\text { Suppressor of in vivo metastasis (Chang et al., } \\
\text { in preparation); }\end{array}$ \\
\hline PC346C & $\begin{array}{l}\text { Xenograft from human } \\
\text { prostate primary tumor }\end{array}$ & CK5 (-) CK8 (+) & Wild-type AR & $\begin{array}{l}\text { Stimulator in PC346C parental cells [54]; } \\
\text { Unresponsive in PC346DCC cells [54]; } \\
\text { Suppressor in PC346-Flu1 cells [54]; } \\
\text { Stimulator in PC346Flu2 cells; } \\
\text { (hydroxyflutamide also be stimulator) [54]. }\end{array}$ \\
\hline
\end{tabular}

Abbreviation: AR, androgen receptor.

pathophysiological roles of the AR in PCa progression and metastasis.

\section{In vitro epithelium-stroma co-culture systems and in vivo animal models}

In the human or rodent prostate, the prostate gland is composed of not only epithelial cells but also stromal cells, endothelial cells and immune cells [55-58]. The epithelium requires the support of the stromal cells for epithelial differentiation, proliferation and apoptosis. The prostatic epithelial cells consist of several subpopulations of epithelium, such as basal cells, intermediate cells and secretory luminal epithelial cells $[59,60]$. Only the mature luminal epithelial cells can secrete certain growth factors and fluids to facilitate sperm maturation and motility $[61,62]$. In the stromal compartments, fibroblasts and smooth muscle cells are the two major cell types and are responsible for the maintenance of the reciprocal balance between epithelial and stromal cells. AR expression is easily detectable in the luminal epithelial cells and is less prominent in the basal/intermediate cells and stromal cells [63]. According to Dr Cunha's tissue recombination experiments [64-66], if the recombinant tissue from $\mathrm{wt}$ urogenital mesenchymal (UGM) cells is reconstituted with testicular feminalization mice $(\mathrm{Tfm})$ urogenital epithelial cells (UGE) [65] and then implanted into the subrenal capsule of severe combined immuno deficient (SCID) mice. The recombinant tissue will develop prostate-like structures, with the secretion of the specific secretory proteins from luminal epithelial cells. However, the recombinant cells taken from wt UGE and Tfm UGM will not develop into prostate-like structures. This recombinant tissue experiment emphasizes the importance of prostate stromal cells in early mouse prostate development. Further, it shows that stromal AR possesses the ability to determine organ fates. In mouse 
or human $\mathrm{PCa}$, the stromal cells could secrete several growth factors $[67,68]$ to stimulate the epithelial budding/ outgrowth, differentiation and maturation.

Under physiological conditions in humans and rodents, epithelial cell growth relies on the support of stromal compartments. The stromal cells secrete a variety of growth factors to stimulate and facilitate the differentiation and growth of epithelial cells. Several paracrine growth factors, such as fibroblast growth factors (FGF-2, FGF-7, FGF10), insulin-like growth factor (IGF) and epidermal growth factor (EGF) [69], have been identified to be involved in the regulation of UGE cells' differentiation, budding and branching.

\subsection{In vitro co-culture system}

The stromal cells seem to be critical in normal prostate development, as well as PCa cell development and progression. Taking the stromal factors into consideration, the in vitro co-culture system will provide a better way to address the epithelial AR functions in cell proliferation and metastasis.

The immortalized human prostate stromal cells WPMY-1 express functional $\mathrm{AR}$ and secrete paracrine growth factors [70]. To examine the stromal AR roles and to maintain intact stromal microenvironments, we applied WPMY-1 cells and their AR knockdown clone (WPMY-1 AR siRNA) to the lower chambers of Matrigel-coated transwells and seeded the PC3-v or PC3-AR9 epithelial cells in the upper chambers [38]. We prepared four groups with different combinations of PC3 (with or without AR) and WPMY-I (scramble or siRNA knockdown): (1) PC3-v and WPMY-1, (2) PC3-v and WPMY-1 AR siRNA, (3) PC3-AR9 and WPMY-1, and (4) PC3-AR9 and WPMY-1 AR siRNA, to study the role of AR in epithelial cell invasion. We observed that the combination of PC $3-\mathrm{V}$ and WPMY-1 showed more abundant invasive cells on the Matrigel-coated chambers and the combination of PC3-AR9 and WPMY-1 AR siRNA showed much less cell invasion compared with other groups [38]. The stromal AR can promote epithelial cell invasion through the secretion of various growth factors, chemokines or cytokines, and AR can act as a suppressor of cell proliferation and invasion of the PC3 epithelial cells. Using this co-culture system, the influence of the stromal cells can be introduced to produce an environment that will more closely resemble true physiological conditions compared with that using single cells under in vitro culture conditions.

\subsection{In vivo tissue recombination model}

The in vitro co-culture system allows us to study the influence of paracrine factors from stromal cells on the epithelium; however, the in vivo situation is much more complicated. The nutritional uptake and blood supply from surrounding and endothelial cells are very important in PCa cell growth and invasion $[7,71]$. The inflammatory cells also infiltrate the prostate and can cause prostatitis, which can alter PCa cell growth and metastasis. Dr. Cunha's group has successfully established the tissue recombination assay to investigate the interaction of epithelial and stromal cells. Recombinant tissue was introduced by inoculation of recombinant cells into the subrenal capsule of SCID mice. The kidney capsule is rich in nutrition and blood flow, and can provide a suitable environment for cell growth. Direct inoculation of recombinant cells into the prostate of SCID mice is an alternative approach. Earlier, we generated four combinations of PC3-v, PC3-AR9, WPMY-1 and WPMY-1 AR siRNA for co-culture study. We directly inoculated these four combinations of cells into the prostates of nude mice $[38,72]$. After 12 weeks, we killed the mice and dissected the recombinant tissue from individual mice. The PC3-v recombined with WPMY-1 cells generated much larger $\mathrm{PCa}$ tumors than the other three groups, and PC3-AR9 recombined with WPMY-1 AR siRNA cells formed much smaller PCa tumors. The results from direct inoculation of PC3-v and WPMY-1 cells were consistent with the in vitro co-culture data, which suggested AR in the PC3 can suppress cell proliferation and AR in WPMY-1 can stimulate PC3 cell growth. For the metastasis study, we also observed that PC3-v and WPMY-1 cells inoculated into the mouse prostate showed larger metastatic pelvic lymph nodes. Contrasting results were obtained from PC3-AR9 and WPMY-1 AR siRNA cells that developed much smaller metastatic pelvic lymph nodes. Therefore, AR in PC3 cells has a suppressor function in cell metastasis, whereas stromal AR can promote $\mathrm{PC} 3$ invasion.

\subsection{Orthotopic transplantable human PCa mice model}

An alternative approach to investigate the role of androgen/AR function in human PCa cells has been established by Wang et al. [73]. First, advanced PCa tumors were obtained from PCa patients undergoing prostatectomy without any neoadjuvant treatment. The tumors were minced into $1 \times 3 \times 3 \mathrm{~mm}^{3}$ pieces and directly grafted into the renal subcapsule of non-obese diabetic-SCID mice implanted with a testosterone pellet (25 mg). After 60-90 days of implantation, the mice were killed. The transplanted PCa tumors were harvested from the kidney, cut into $2 \mathrm{~mm}^{3}$ pieces, and then grafted into the anterior prostate of SCID mice. After the grafting procedure, the mice were killed at different time points to examine the primary tumors and metastatic tumors in the lymph node, bone, lung and liver [73]. Using this orthotopic transplantable mouse model, we can remove androgen through castration or restore androgen by implanting a testosterone pellet to study the androgen/AR signaling effects on human $\mathrm{PCa}$ growth and metastasis. 
The benefit of this mouse model is that small pieces of PCa tumors still maintain the original cell composition, such as epithelial cells and stromal cells, as well as their microenvironments. These complete microenvironments can supply and foster PCa growth, and we can manipulate the androgen levels in mice to manipulate androgen/AR effects on $\mathrm{PCa}$ growth and metastasis. However, in this orthotopic human PCa transplantable mouse model, the systemic androgen levels will affect not only the epithelia but also the stromal cells, and we cannot examine AR function in specific cells. To overcome these limitations, the cre/loxp system was used to generate specific AR knockout mice to study AR roles in individual cells. This review discusses the currently available and popular transgenic mouse models and epithelial AR roles in $\mathrm{PCa}$ proliferation and metastasis.

3.4 Available genetically engineered mouse (GEM) models for PCa study and manifestation of epithelial AR functions in transgenic mice

To study PCa in mice, several GEM models have been generated and widely used. The principles of generation of GEM models are either over-expression of an oncogene (gain-of-function mutation) or knockout of tumor suppressor genes (loss-of-function mutation) to initiate tumorigenesis $[74,75]$. Popular transgenic mouse models will be discussed here and we will also discuss how to delineate AR functions in selective cells by generating transgenic compound mice. The TRAMP mice were generated over 10 years ago [76-78] and the prostatic epithelial specific promoter (probasin promoter) was used to drive the expression of SV40 LT-ag. In this TRAMP mouse, the prostate progressively develops from early prostatic epithelial neoplasia (PIN) to metastatic Pca, which mimics the pathological progression of human $\mathrm{PCa}$. To study the prostatic epithelial AR function in TRAMP mice, we generated pes-ARKO-TRAMP compound mouse $[38,72,79]$. pes-ARKO-TRAMP mice spontaneously develop PCa, and progressively and simultaneously knock out epithelial AR. The pes-ARKO-TRAMP mice develop larger primary tumors and die earlier than wtTRAMP littermate controls. The prostate tumors of pesARKO-TRAMP mice show more apoptosis and a higher proliferation index, resulting in higher cell turnover rates. In the metastasis study, the pes-ARKO-TRAMP mice developed bigger metastatic pelvic lymph nodes than wt control mice at 24 weeks of age. The data from pes-ARKO-TRAMP and its wt control suggested that epithelial AR can suppress tumor growth and metastasis. The suppressor roles of AR in pes-ARKO-TRAMP correlated with AR functions in $\mathrm{PC} 3$, but it contradicted the AR roles in $\mathrm{LNCaP}$ and CWR22Rv1 cells.

Another well-characterized and well-used preclinical mouse model is the Phosphatase and Tensin homologue deleted on chromosome 10 (PTEN) knockout mice. The PTEN tumor suppressor gene was frequently identified with deletions or mutations in human cancers [80, 81]. PTEN alteration has been implicated in human $\mathrm{PCa}$ development. PTEN deletions or mutations were found in $30 \%$ of primary PCas and $63 \%$ of metastatic PCa tumors [82]. The PTEN homozygous null mice were embryonic lethal, suggesting that PTEN is essential for embryonic development. The PTEN $^{+/}$male mice developed early PIN lesions by $12-17$ weeks with a high proliferation index, but did not further advance to adenocarcinoma or metastatic PCa [81]. To further study the metastasis of PTEN knockout mice, compound mutant mice $\left(\mathrm{PTEN}^{+/-}, \mathrm{NKX} 3.1^{+/}\right.$) were generated [83-85]. NKX3.1 is a homeobox gene that specifically expresses in the prostate, and the allelic deletion in prostatic neoplasia has been implicated in PCa initiation. The PTEN ${ }^{+/}$, NKX3.1 $1^{+/-}$mutant mice can proceed into high-grade PIN by 6 months and develop invasive prostate adenocarcinoma after 12 months of age. By taking advantage of these well-characterized mutant mice, we can generate prostatic epithelial specific ARKO mice with heterozygous mutations of $\mathrm{PTEN}^{+/}, \mathrm{NKX} 3.1^{+/}$ to elucidate the role of epithelial AR at early stages of primary tumor growth and at later stages of cell metastasis.

\section{Summary and future directions}

Each cell line with its own characteristics might respond differently to androgen/AR signaling. The cellular and molecular alterations of epithelial cells and their microenvironments are complicated and it is difficult to use a single cell line to address these important issues and study the pathophysiological functions of AR. Furthermore, in vitro cell culture under simplified, two-dimensional conditions might not accurately reflect the physiological growth status of cancer cells. Using a single cell line to study the role of AR in human PCa has obvious biases and disadvantages.

Therefore, it is necessary to develop better strategies to delineate the pathophysiologic roles of AR in PCa progression and metastasis. The in vitro co-culture system [38], in vivo tissue recombination models [60] and transplantable human PCa mouse models $[72,86]$ are well established for the study of PCa. These models could more closely mimic human PCa progression and metastasis by considering the stromal factors and extra-cellular microenvironments. With the rapid development of transgenic technology, some spontaneous PCa mouse models [78, 82, 87] and prostate-specific AR knockout mouse models [38, 72, 79] have also been well established. These models might yield important contributions and revolutionize research on AR and PCa. Having access to both in vitro cell lines 
and in vivo mouse models may provide better strategies for studying the role of AR in $\mathrm{PCa}$ and lead to more convincing data and robust conclusions.

\section{References}

1 Sim HG, Cheng CW. Changing demography of prostate cancer in Asia. Eur J Cancer 2005; 41: 834-45.

2 Heinlein CA, Chang C. Androgen receptor in prostate cancer. Endocr Rev 2004; 25: 276-308.

3 Huggins C, Hodges CV. Studies on prostatic cancer. I. The effect of castration, of estrogen and of androgen injection on serum phosphatases in metastatic carcinoma of the prostate. Cancer Res 1941; 1: 293-7.

4 Chen CD, Welsbie DS, Tran C, Baek SH, Chen R, et al. Molecular determinants of resistance to antiandrogen therapy. Nat Med 2004; 10: 33-9.

5 Edwards J, Krishna NS, Grigor KM, Bartlett JM. Androgen receptor gene amplification and protein expression in hormone refractory prostate cancer. Br J Cancer 2003; 89: 552-6.

6 Rahman M, Miyamoto H, Chang C. Androgen receptor coregulators in prostate cancer: mechanisms and clinical implications. Clin Cancer Res 2004; 10: 2208-19.

7 Ricke WA, Wang Y, Kurita T, Hayward SW, Cunha GR. Hormonal and stromal regulation of normal and neoplastic prostatic growth. Prog Mol Subcell Biol 2005; 40: 183-216.

8 Lin HK, Yeh S, Kang HY, Chang C. Akt suppresses androgeninduced apoptosis by phosphorylating and inhibiting androgen receptor. Proc Natl Acad Sci USA 2001; 98: 7200-05.

9 van Bokhoven A, Varella-Garcia M, Korch C, Johannes WU, Smith EE, et al. Molecular characterization of human prostate carcinoma cell lines. Prostate 2003; 57: 205-25.

10 Horoszewicz JS, Leong SS, Chu TM, Wajsman ZL, Friedman M, et al. The LNCaP cell line - a new model for studies on human prostatic carcinoma. Prog Clin Biol Res 1980; 37: 115-32.

11 Veldscholte J, Ris-Stalpers C, Kuiper GG, Jenster G, Berrevoets $\mathrm{C}$, et al. A mutation in the ligand binding domain of the androgen receptor of human $\mathrm{LNCaP}$ cells affects steroid binding characteristics and response to anti-androgens. Biochem Biophys Res Commun 1990; 173: 534-40.

12 Yang Q, Fung KM, Day WV, Kropp BP, Lin HK. Androgen receptor signaling is required for androgen-sensitive human prostate cancer cell proliferation and survival. Cancer Cell Int 2005; 5: 8 .

13 Compagno D, Merle C, Morin A, Gilbert C, Mathieu JR, et al. SIRNA-directed in vivo silencing of androgen receptor inhibits the growth of castration-resistant prostate carcinomas. PLoS ONE 2007; 2: e1006.

14 Liao X, Tang S, Thrasher JB, Griebling TL, Li B. Smallinterfering RNA-induced androgen receptor silencing leads to apoptotic cell death in prostate cancer. Mol Cancer Ther 2005; 4: 505-15.

15 Haag P, Bektic J, Bartsch G, Klocker H, Eder IE. Androgen receptor down regulation by small interference RNA induces cell growth inhibition in androgen sensitive as well as in androgen independent prostate cancer cells. J Steroid Biochem Mol Biol 2005; 96: 251-8.

16 Eder IE, Culig Z, Ramoner R, Thurnher M, Putz T, et al. Inhibition of LncaP prostate cancer cells by means of androgen receptor antisense oligonucleotides. Cancer Gene Ther 2000; 7 : 997-1007.

17 Eder IE, Hoffmann J, Rogatsch H, Schafer G, Zopf D, et al. Inhibition of $\mathrm{LNCaP}$ prostate tumor growth in vivo by an antisense oligonucleotide directed against the human androgen receptor. Cancer Gene Ther 2002; 9: 117-25.

18 Kokontis J, Takakura K, Hay N, Liao S. Increased androgen receptor activity and altered c-myc expression in prostate cancer cells after long-term androgen deprivation. Cancer Res 1994; 54: 1566-73.

19 Igawa T, Lin FF, Lee MS, Karan D, Batra SK, et al. Establishment and characterization of androgen-independent human prostate cancer LNCaP cell model. Prostate 2002; 50: 222-35.

20 Iwasa Y, Mizokami A, Miwa S, Koshida K, Namiki M. Establishment and characterization of androgen-independent human prostate cancer cell lines, LN-REC4 and LNCaP-SF, from LNCaP. Int J Urol 2007; 14: 233-9.

21 Yuan TC, Veeramani S, Lin FF, Kondrikou D, Zelivianski S, et al. Androgen deprivation induces human prostate epithelial neuroendocrine differentiation of androgen-sensitive LNCaP cells. Endocr Relat Cancer 2006; 13: 151-67.

22 Joly-Pharaboz MO, Soave MC, Nicolas B, Mebarki F, Renaud $\mathrm{M}$, et al. Androgens inhibit the proliferation of a variant of the human prostate cancer cell line LNCaP. J Steroid Biochem Mol Biol 1995; 55: 67-76.

23 Kokontis JM, Hay N, Liao S. Progression of LNCaP prostate tumor cells during androgen deprivation: hormone-independent growth, repression of proliferation by androgen, and role for p27Kip1 in androgen-induced cell cycle arrest. Mol Endocrinol 1998; 12: 941-53.

24 Joly-Pharaboz MO, Ruffion A, Roch A, Michel-Calemard L, Andre $\mathrm{J}$, et al. Inhibition of growth and induction of apoptosis by androgens of a variant of LNCaP cell line. J Steroid Biochem Mol Biol 2000; 73: 237-49.

25 Chuu CP, Hiipakka RA, Fukuchi J, Kokontis JM, Liao S. Androgen causes growth suppression and reversion of androgenindependent prostate cancer xenografts to an androgen-stimulated phenotype in athymic mice. Cancer Res 2005; 65: 2082-4.

26 Joly-Pharaboz MO, Kalach JJ, Pharaboz J, Chantepie J, Nicolas $\mathrm{B}$, et al. Androgen inhibits the growth of carcinoma cell lines established from prostate cancer xenografts that escape androgen treatment. J Steroid Biochem Mol Biol 2008; 111: 50-9.

27 Soto AM, Lin TM, Sakabe K, Olea N, Damassa DA, et al. Variants of the human prostate $\mathrm{LNCaP}$ cell line as tools to study discrete components of the androgen-mediated proliferative response. Oncol Res 1995; 7: 545-58.

28 Takahashi H, Furusato M, Allsbrook Jr WC, Nishii H, Wakui S, et al. Prevalence of androgen receptor gene mutations in latent prostatic carcinomas from Japanese men. Cancer Res 1995; 55: 1621-4.

29 Marcelli M, Ittmann M, Mariani S, Sutherland R, Nigam R, et al. Androgen receptor mutations in prostate cancer. Cancer Res 2000; 60: 944-9.

30 Suzuki H, Sato N, Watabe Y, Masai M, Seino S, et al. Androgen receptor gene mutations in human prostate cancer. J Steroid Biochem Mol Biol 1993; 46: 759-65.

31 Tilley WD, Buchanan G, Hickey TE, Bentel JM. Mutations in the androgen receptor gene are associated with progression of human prostate cancer to androgen independence. Clin Cancer Res 1996; 2: 277-85. 
32 Kaighn ME, Narayan KS, Ohnuki Y, Lechner JF, Jones LW. Establishment and characterization of a human prostatic carcinoma cell line (PC-3). Invest Urol 1979; 17: 16-23.

33 Litvinov IV, Antony L, Dalrymple SL, Becker R, Cheng L, et al. PC3, but not DU145, human prostate cancer cells retain the coregulators required for tumor suppressor ability of androgen receptor. Prostate 2006; 66: 1329-38.

34 Yuan S, Trachtenberg J, Mills GB, Brown TJ, Xu F, et al. Androgen-induced inhibition of cell proliferation in an androgeninsensitive prostate cancer cell line (PC-3) transfected with a human androgen receptor complementary DNA. Cancer Res 1993; 53: 1304-11.

35 Altuwaijri S, Wu CC, Niu YJ, Mizokami A, Chang HC, et al. Expression of human AR cDNA driven by its own promoter results in mild promotion, but not suppression, of growth in human prostate cancer PC-3 cells. Asian J Androl 2007; 9: $181-8$.

36 Shen R, Sumitomo M, Dai J, Harris A, Kaminetzky D, et al. Androgen-induced growth inhibition of androgen receptor expressing androgen-independent prostate cancer cells is mediated by increased levels of neutral endopeptidase. Endocrinology 2000; 141: 1699-704.

$37 \mathrm{Xu}$ XF, Zhou SW, Zhang X, Ye ZQ, Zhang JH, et al. Prostate androgen-regulated gene: a novel potential target for androgenindependent prostate cancer therapy. Asian J Androl 2006; 8: 455-62.

38 Niu Y, Altuwaijri S, Lai KP, Wu CT, Ricke WA, et al. Androgen receptor is a tumor suppressor and proliferator in prostate cancer. Proc Natl Acad Sci USA 2008; 105: 12182-7.

39 Wilson SS, Crawford ED. Controversies of androgen ablation therapy for metastatic prostate cancer. Curr Pharm Des 2006; 12: 799-805.

40 van Leenders GJ, Aalders TW, Hulsbergen-van de Kaa CA, Ruiter DJ, Schalken JA. Expression of basal cell keratins in human prostate cancer metastases and cell lines. J Pathol 2001; 195: 563-70.

41 Bruchovsky N, Rennie PS, Coldman AJ, Goldenberg SL, To $\mathrm{M}$, et al. Effects of androgen withdrawal on the stem cell composition of the Shionogi carcinoma. Cancer Res 1990; 50: 2275-82.

42 Stone KR, Mickey DD, Wunderli H, Mickey GH, Paulson DF. Isolation of a human prostate carcinoma cell line (DU 145). Int J Cancer 1978; 21: 274-81.

43 Chlenski A, Nakashiro K, Ketels KV, Korovaitseva GI, Oyasu R. Androgen receptor expression in androgen-independent prostate cancer cell lines. Prostate 2001; 47: 66-75.

44 Scaccianoce E, Festuccia C, Dondi D, Guerini V, Bologna M, et al. Characterization of prostate cancer DU145 cells expressing the recombinant androgen receptor. Oncol Res 2003; 14: 10112.

45 Nagakawa O, Akashi T, Hayakawa Y, Junicho A, Koizumi K, et al. Differential expression of integrin subunits in DU-145/AR prostate cancer cells. Oncol Rep 2004; 12: 837-41.

46 Akashi T, Koizumi K, Nagakawa O, Fuse H, Saiki I. Androgen receptor negatively influences the expression of chemokine receptors (CXCR4, CCR1) and ligand-mediated migration in prostate cancer DU-145. Oncol Rep 2006; 16: 831-6.

47 Sramkoski RM, Pretlow II TG, Giaconia JM, Pretlow TP, Schwartz $\mathrm{S}$, et al. A new human prostate carcinoma cell line, 22Rv1. In Vitro Cell Dev Biol Anim 1999; 35: 403-9.
48 Nagabhushan M, Miller CM, Pretlow TP, Giaconia JM, Edgehouse NL, et al. CWR22: the first human prostate cancer xenograft with strongly androgen-dependent and relapsed strains both in vivo and in soft agar. Cancer Res 1996; 56: 3042-6.

49 Wainstein MA, He F, Robinson D, Kung HJ, Schwartz S, et al. CWR22: androgen-dependent xenograft model derived from a primary human prostatic carcinoma. Cancer Res 1994; 54: 6049-52.

50 Tepper CG, Boucher DL, Ryan PE, Ma AH, Xia L, et al. Characterization of a novel androgen receptor mutation in a relapsed CWR22 prostate cancer xenograft and cell line. Cancer Res 2002; 62: 6606-14.

51 Yeh S, Hu YC, Wang PH, Xie C, Xu Q, et al. Abnormal mammary gland development and growth retardation in female mice and MCF7 breast cancer cells lacking androgen receptor. J Exp Med 2003; 198: 1899-908.

52 van Weerden WM, de Ridder CM, Verdaasdonk CL, Romijn JC, van der Kwast TH, et al. Development of seven new human prostate tumor xenograft models and their histopathological characterization. Am J Pathol 1996; 149: 1055-62.

53 van Weerden WM, Romijn JC. Use of nude mouse xenograft models in prostate cancer research. Prostate 2000; 43: 263-71.

54 Marques RB, Erkens-Schulze S, de Ridder CM, Hermans KG, Waltering $\mathrm{K}$, et al. Androgen receptor modifications in prostate cancer cells upon long-term androgen ablation and antiandrogen treatment. Int J Cancer 2005; 117: 221-9.

55 Cunha GR. Epithelial-stromal interactions in development of the urogenital tract. Int Rev Cytol 1976; 47: 137-94.

56 Cunha GR, Cooke PS, Kurita T. Role of stromal-epithelial interactions in hormonal responses. Arch Histol Cytol 2004; 67: 417-34.

57 Cunha GR, Donjacour A. Stromal-epithelial interactions in normal and abnormal prostatic development. Prog Clin Biol Res 1987; 239: 251-72.

58 Cunha GR, Donjacour AA, Sugimura Y. Stromal-epithelial interactions and heterogeneity of proliferative activity within the prostate. Biochem Cell Biol 1986; 64: 608-14.

59 Hayward SW, Baskin LS, Haughney PC, Cunha AR, Foster BA, et al. Epithelial development in the rat ventral prostate, anterior prostate and seminal vesicle. Acta Anat (Basel) 1996; 155: 81-93.

60 Hayward SW, Haughney PC, Rosen MA, Greulich KM, Weier HU, et al. Interactions between adult human prostatic epithelium and rat urogenital sinus mesenchyme in a tissue recombination model. Differentiation 1998; 63: 131-40.

61 Ganjam VK, Amann RP. Steroids in fluids and sperm entering and leaving the bovine epididymis, epididymal tissue, and accessory sex gland secretions. Endocrinology 1976; 99: 161830.

62 Robert M, Gagnon C. Sperm motility inhibitor from human seminal plasma: presence of a precursor molecule in seminal vesicle fluid and its molecular processing after ejaculation. Int J Androl 1994; 17: 232-40.

63 Litvinov IV, De Marzo AM, Isaacs JT. Is the Achilles' heel for prostate cancer therapy a gain of function in androgen receptor signaling? J Clin Endocrinol Metab 2003; 88: 2972-82.

64 Cunha GR, Alarid ET, Turner T, Donjacour AA, Boutin EL, et al. Normal and abnormal development of the male urogenital tract. Role of androgens, mesenchymal-epithelial interactions, 
and growth factors. J Androl 1992; 13: 465-75.

65 Cunha GR, Chung LW. Stromal-epithelial interactions-I. Induction of prostatic phenotype in urothelium of testicular feminized (Tfm/y) mice. J Steroid Biochem 1981; 14: 1317-24.

66 Cunha GR, Lung B. The importance of stroma in morphogenesis and functional activity of urogenital epithelium. In Vitro 1979; 15 : 50-71.

67 Chung LW, Cunha GR. Stromal-epithelial interactions-II. Regulation of prostatic growth by embryonic urogenital sinus mesenchyme. Prostate 1983; 4: 503-11.

68 Cunha GR, Foster B, Thomson A, Sugimura Y, Tanji N, et al. Growth factors as mediators of androgen action during the development of the male urogenital tract. World J Urol 1995; 13: $264-76$.

69 Culig Z, Hobisch A, Cronauer MV, Radmayr C, Hittmair A, et al. Regulation of prostatic growth and function by peptide growth factors. Prostate 1996; 28: 392-405.

70 Webber MM, Trakul N, Thraves PS, Bello-DeOcampo D, Chu WW, et al. A human prostatic stromal myofibroblast cell line WPMY-1: a model for stromal-epithelial interactions in prostatic neoplasia. Carcinogenesis 1999; 20: 1185-92.

71 Ricke WA, Ishii K, Ricke EA, Simko J, Wang Y, et al. Steroid hormones stimulate human prostate cancer progression and metastasis. Int J Cancer 2006; 118: 2123-31.

72 Niu Y, Altuwaijri S, Yeh S, Lai KP, Yu S, et al. Targeting the stromal androgen receptor in primary prostate tumors at earlier stages. Proc Natl Acad Sci USA 2008; 105: 12188-93.

73 Wang Y, Xue H, Cutz JC, Bayani J, Mawji NR, et al. An orthotopic metastatic prostate cancer model in SCID mice via grafting of a transplantable human prostate tumor line. Lab Invest 2005; 85: 1392-404.

74 Pienta KJ, Abate-Shen C, Agus DB, Attar RM, Chung LW, et al. The current state of preclinical prostate cancer animal models. Prostate 2008; 68: 629-39.

75 Shappell SB, Thomas GV, Roberts RL, Herbert R, Ittmann $\mathrm{MM}$, et al. Prostate pathology of genetically engineered mice: definitions and classification. The consensus report from the Bar Harbor meeting of the Mouse Models of Human Cancer Consortium Prostate Pathology Committee. Cancer Res 2004; 64: $2270-305$.
76 Foster BA, Gingrich JR, Kwon ED, Madias C, Greenberg NM Characterization of prostatic epithelial cell lines derived from transgenic adenocarcinoma of the mouse prostate (TRAMP) model. Cancer Res 1997; 57: 3325-30.

77 Gingrich JR, Barrios RJ, Kattan MW, Nahm HS, Finegold MJ, et al. Androgen-independent prostate cancer progression in the TRAMP model. Cancer Res 1997; 57: 4687-91.

78 Gingrich JR, Greenberg NM. A transgenic mouse prostate cancer model. Toxicol Pathol 1996; 24: 502-4.

79 Wu CT, Altuwaijri S, Ricke WA, Huang SP, Yeh S, et al. Increased prostate cell proliferation and loss of cell differentiation in mice lacking prostate epithelial androgen receptor. Proc Natl Acad Sci USA 2007; 104: 12679-84.

80 Dong JT. Chromosomal deletions and tumor suppressor genes in prostate cancer. Cancer Metastasis Rev 2001; 20: 173-93.

81 Podsypanina K, Ellenson LH, Nemes A, Gu J, Tamura M, et al. Mutation of Pten/Mmac1 in mice causes neoplasia in multiple organ systems. Proc Natl Acad Sci USA 1999; 96: 1563-8.

82 Wang S, Gao J, Lei Q, Rozengurt N, Pritchard C, et al. Prostatespecific deletion of the murine Pten tumor suppressor gene leads to metastatic prostate cancer. Cancer Cell 2003; 4: 209-21.

83 Abate-Shen C, Banach-Petrosky WA, Sun X, Economides KD, Desai $\mathrm{N}$, et al. Nkx3.1; Pten mutant mice develop invasive prostate adenocarcinoma and lymph node metastases. Cancer Res 2003; 63: 3886-90.

84 Banach-Petrosky W, Jessen WJ, Ouyang X, Gao H, Rao J, et al. Prolonged exposure to reduced levels of androgen accelerates prostate cancer progression in Nkx3.1; Pten mutant mice. Cancer Res 2007; 67: 9089-96.

85 Lei Q, Jiao J, Xin L, Chang CJ, Wang S, et al. NKX3.1 stabilizes p53, inhibits AKT activation, and blocks prostate cancer initiation caused by PTEN loss. Cancer Cell 2006; 9: 367-78.

86 Klein KA, Reiter RE, Redula J, Moradi H, Zhu XL, et al. Progression of metastatic human prostate cancer to androgen independence in immunodeficient SCID mice. Nat Med 1997; 3: 402-8.

87 Kim MJ, Cardiff RD, Desai N, Banach-Petrosky WA, Parsons $\mathrm{R}$, et al. Cooperativity of $\mathrm{Nkx} 3.1$ and Pten loss of function in a mouse model of prostate carcinogenesis. Proc Natl Acad Sci USA 2002; 99: 2884-9. 